\title{
Effects of scopolamine on anterograde and remote memory in humans
}

\author{
ALEXANDER I. TRÖSTER and WILLIAM W. BEATTY \\ North Dakota State University, Fargo, North Dakota \\ and \\ R. DENNIS STATON and ANNE G. RORABAUGH \\ Fargo Veterans Administration Medical Center, Fargo, North Dakota
}

\begin{abstract}
Previous research with laboratory animals indicates that anterograde-memory functions are more easily disrupted by anticholinergic drug treatment than are established reference memories. In studies with human subjects, some measures of established (remote) memory appear to be disrupted by anticholinergic agents, while other measures of remote memory have proven insensitive to anticholinergic treatments. To clarify the effects of anticholinergic treatment on remote memory in humans, we studied the effects of administering 0.5 or $0.8 \mathrm{mg}$ scopolamine to middleaged men on a battery of tests of anterograde and remote memory. Dose-related impairments on measures of anterograde short-term memory and verbal and nonverbal learning were observed and, in addition, performance on a category-fluency task, which required retrieval of information from established semantic memory, was disrupted. In contrast, measures of remote memory that required identification of photographs of famous people, recall of past public events, and display of geographical knowledge were not affected by scopolamine treatment. Implications of the findings for drug models of memory failure in dementia are discussed.
\end{abstract}

When centrally active anticholinergic drugs, such as atropine and scopolamine, are administered to various animal species prior to training, deficits in acquisition and retention are observed on a variety of tests (for reviews, see Collerton, 1986; Spencer \& Lal, 1983). In humans, these agents produce anterograde memory deficits in short-term memory (STM; Beatty, Butters, \& Janowsky, 1986; Caine, Weingartner, Ludlow, Cudahy, \& Wehry, 1981 ) and in long-term recall and recognition of verbal and nonverbal material (Caine et al., 1981; Crow \& Grove-White, 1973; Frith, Richardson, Samuel, Crow, \& McKenna, 1984; Ghoneim \& Mewaldt, 1975; Mewaldt \& Ghoneim, 1979; Sitaram, Weingartner, \& Gillin, 1978).

The effects of anticholinergic treatment on memories established prior to drug administration are less clear. In animals, several studies indicate that acquisition and working memory (WM) are more vulnerable to disruption by anticholinergic agents than are established reference

The authors gratefully acknowledge the support and encouragement of Gerald Vosika, Fargo VA Medical Center. We also express appreciation to Leon Thal and Jeffrey Cummings for their insightful comments on an earlier version of this manuscript, and to Doris Hertsgaard for statistical consultation. This research was funded by Biomedical Research Support Grant 2 S07 RR07206 to North Dakota State University and was presented in part at the annual meeting of the International Neuropsychological Society, Washington, D.C., February, 1987. Alexander Tröster's present address is UCSD-SDSU Clinical Psychology Program, 6363 Alvarado Ct., Suite 103, San Diego, CA 92182. Requests for reprints may be sent to William W. Beatty, Department of Psychology, North Dakota State University, Fargo, ND 58105. memories (Beatty \& Bierley, 1985; Burešová, Bolhuis, \& Bureš, 1986; Levy, Kluge, \& Elsmore, 1983; Santi, Hanemaayer, \& Reason, 1987; Whishaw, 1985; Wirsching, Beninger, Jhamandas, Boegman, \& El-Defrawy, 1984). In one study (Okaichi \& Jarrard, 1982), however, reference memory and WM were equally affected by scopolamine treatment. Drachman and Leavitt (1974) found that administration of scopolamine to human subjects had no effect on their WAIS verbal IQ scores, which reflect mainly well-established memories. Other data (Caine et al., 1981; Drachman \& Leavitt, 1974) demonstrate that scopolamine, at doses of $0.8 \mathrm{mg}$ or higher, reduces output of young normal subjects on verbal-fluency tasks, which Weingartner (1985) considers to be a measure of access to knowledge memory. Using a dose of $0.5 \mathrm{mg}$ scopolamine, which was sufficient to impair acquisition of a free-recall task, Beatty et al. (1986) found no effect on verbal fluency, suggesting that the drug effects on this task may be dose-related.

To clarify the influences of anticholinergic agents on verbal and spatial memory of normal human subjects, we studied the effects of administering 0.5 and $0.8 \mathrm{mg}$ scopolamine on a battery of verbal and nonverbal tests that assessed anterograde memory and retrieval of established knowledge. Since verbal-fluency tests place a premium on sustained and rapid responding, deficits on these tests following scopolamine challenge could arise from the sedating effects of this drug rather than from blockade of cholinergic circuits essential for accessing established memories. To address this issue, our battery of remote-memory measures included tests that required 
identification of famous people and recall of past public events and geographical knowledge. These measures place much less emphasis on speed of responding than do verbal-fluency measures, which were also included in our study.

\section{METHOD}

\section{Subjects}

This study was performed in accordance with established principles for the conduct of research involving drugs in human subjects (American Psychological Association, 1972; 1981). The protocol was approved by three independent institutional review boards. Potential subjects were contacted by the principal investigator, who thoroughly explained the purpose of the study and the potential side effects of scopolamine treatment (e.g., drowsiness, blurred vision, nausea, increased heart rate, hallucinations). Persons who remained interested in participating were medically screened prior to their inclusion in the study. Individuals with central nervous system disease, a history of psychiatric, cardiac, gastrointestinal, or urogenital illness or of alcohol or drug abuse were excluded. Persons with any other systemic disorder were admitted to the study only if the attending physician concluded that scopolamine treatment posed no risk and if such a disorder would not affect neuropsychological test results. To further reduce risk to the subjects, they were transported to and from the test site by the investigators on each of the three testing sessions. They were encouraged to refrain from using alcohol or other psychoactive drugs and from operating machinery or vehicles until they were certain that the effects of scopolamine had completely dissipated. Subjects were told that drug effects could persist for up to $24 \mathrm{~h}$. Throughout their involvement in the study, their right to withdraw was emphasized. Subjects provided written informed consent and were paid for their participation.

Thirteen healthy males aged 31 to 59 years $($ Mean $=39.2)$, with an average education of 16.9 years (Range: 12-20), completed the study. The oldest subject experienced extreme sedation and acute delirium after scopolamine treatment; his test performance is discussed separately. Analyses were carried out on the data from 12 subjects aged 31 to 46 years (Mean $=37.5$ ), with an average education of 16.8 years.

\section{Materials and Procedure}

Each subject in the study was tested on three separate occasions, $30 \mathrm{~min}$ following I.M. injection of $1 \mathrm{ml}$ of 0.0 (i.e., physiological saline), 0.5 , or $0.8 \mathrm{mg}$ scopolamine $\mathrm{HBr}$ (American Quinine) in saline vehicle. Sessions were separated by at least $48 \mathrm{~h}$, and the order of treatments was counterbalanced between subjects. Both the subjects and the experimenter were nominally blind to the treatment conditions. Since the central and peripheral effects of scopolamine are distinctive, however, the subjects and the experimenter could readily distinguish drug from placebo conditions. The pool of items for the remote-memory battery was large enough to construct only three equivalent forms. Since we wished to study two doses of the centrally active form of scopolamine, we could use only a single-placebo condition. We elected not to employ a peripherally active anticholinergic drug as the placebo control agent, because previous studies (Bartus, Dean, Beer \& Lippa, 1982; Beatty et al., 1986; Sitaram et al., 1978) have demonstrated that such drugs have no detectable effect on learning or memory. Tests were administered in the order in which they are described below.

Free recall. The free-recall task used three equivalent 14-word lists, each consisting of 7 high-imagery and 7 low-imagery words. Words were read to the subject at the rate of 1 every $2 \mathrm{sec}$. After the whole list had been read, the subjects immediately attempted to recall as many words as possible in whatever order they wished. Once the subject stated that he could not recall any more words, or he had recalled all the words, the list of words was read again in a different order. This procedure was followed for a total of five presentation-recall trials. Forty minutes after the final presentation-recall trial, the subject was again asked to recall as many words as possible.

Remote-memory battery (RMB). A revised version of the battery originally constructed by Albert, Butters, \& Levin (1979) was used. We updated this battery (Beatty, Salmon, Bernstein, \& Butters, 1987), adding items from the 1970 s and 1980s. The revised RMB required identification of 75 photographs of famous faces and 75 public events from the 1940s, 1950s, 1960s, 1970s, and 1980s. Fifteen items of each type were drawn from each decade. Three equivalent 50 -item forms of the battery were constructed for use in the present study. The subjects were allowed a maximum of $30 \mathrm{sec}$ to name the person in each photograph or to answer each public events question. No cues were given to aid memory.

Fargo map test (FMT). This test, designed to evaluate remote geographic/spatial memory (Beatty, 1988), was abbreviated for present purposes. It consisted of two outline maps, one of the United States (U.S.) and one of the tristate region (North Dakota, South Dakota, Minnesota). The subjects were required to locate 14 geographical featurs (cities, rivers, oceans, mountains) on each map by writing the numbers identifying these items as closely as possible to their actual locations on the maps.

The FMT was self-administered. Each item was scored on a 0-1 point scale, with half points given for close approximations. Two raters, blind to the drug condition, independently evaluated performance. Interrater reliabilities were high $(r=.99$ and .97 for the U.S. and regional maps, respectively).

New map test (NMT). The NMT was designed to assess the acquisition of unfamiliar geographical/spatial information. Three equivalent forms were constructed on the basis of data obtained from a pilot study utilizing North Dakota State University undergraduates. The subjects were given an outline map of three fictitious states that contained a total of 15 cities with imaginary names and were told to study the state names and the locations of the cities. After $60 \mathrm{sec}$, the study map was removed and the subjects were presented with a test map, at the top of which were listed the names of the cities with their identifying numbers. The subjects were required to identify the proper location of each city by writing its identifying number as close as possible to its location on the study map. When the subjects could locate no more cities, they were again presented with the study map for $60 \mathrm{sec}$. This procedure was repeated for a total of four presentation-recall trials. The maps were scored by assigning a score of $0-1$ for each item; close approximations received a half point. The interrater reliability between two independent scorers was .99 .

Symptom checklist. This self-report questionnaire, based on the revised version of the SCL-90 (Derogatis, 1977), required the subjects to indicate, on a 5 -point scale $(0=$ absence of the symptom, $4=$ marked presence of the symptom), the extent to which they were experiencing 17 different symptoms. Items describing physical (e.g., tachycardia, dry mouth, blurred vision, nausea) and psychological (e.g., tiredness, distractibility, hallucinations) symptoms that may arise as adverse effects of scopolamine treatment were selected. Items identifying depressive symptoms were also included.

Verbal-fluency tests. First, a modified version of the controlled oral word association (FAS) test (Borkowski, Benton, \& Spreen, 1967) was administered. The subjects were allowed $60 \mathrm{sec}$ to produce as many different words as possible that began with the letter F. They were told that proper names were not allowable answers. The procedure then was repeated with the letters $A$ and $S$. Immediately after completion of this letter-fluency task, the subjects were given a category-fluency task in which they were asked to name as many different animals as possible in a 60 -sec interval.

Brown-Peterson short-term memory test. The version of the Brown-Peterson task used here has previously been shown to be 
sensitive to treatment with $0.5 \mathrm{mg}$ scopolamine (Beatty et al., 1986). The subjects were read a list of four unrelated words followed by a three-digit number, from which they counted backwards by $3 \mathrm{~s}$ for $15 \mathrm{sec}$. They then attempted to recall as many of the words as possible. After a 10-sec recall period, they were read another fourword list, and this procedure was repeated for a total of 10 trials (i.e., 40 words). The subjects were given one of three different but equivalent forms during each of the testing sessions.

\section{RESULTS}

On the symptom checklist, scopolamine treatment produced dose-dependent increases in self-reported feelings of energy depletion, tiredness, trouble concentrating, blurred vision, and dryness of the mouth $\left[F_{\mathrm{s}}(2,22)\right.$ $>8.32, p \mathrm{~s}<.005]$. Except for the delirious subject, feelings of depression and hallucinations were not reported.

\section{Anterograde-Memory Tests}

As shown in Table 1, scopolamine administration impaired performance on the free-recall task. Repeated measures ANOVA for the five trials of immediate recall revealed a significant effect of drug dose $[F(2,22)=$ $21.09, p<.001$ ]. Subsequent $t$ tests demonstrated significant differences between the saline condition and both drug doses. In addition, differences in recall after treatment with the two doses of scopolamine were significant (all $p s<.05$ ).

A similar dose-dependent effect of scopolamine treatment was observed on delayed recall $[F(2,22)=22.66$, $p<.001$, followed by subsequent $t$ tests]. On both the immediate- and delayed-recall tasks, high-imagery words were recalled better than were low-imagery words $[F \mathrm{~s}(1,11)>14.86, p \mathrm{~s}<.005]$, but the imagery $\times$ drug dose interaction was not significant for either the immediate- or delayed-recall tests.

Acquisition of new spatial information was also impaired in a dose-dependent fashion by scopolamine administration (Table 1). ANOVA revealed significant main

Table 1

Mean Performances on the Anterograde-Memory Measures

\begin{tabular}{|c|c|c|c|}
\hline \multirow[b]{2}{*}{ Task } & \multicolumn{3}{|c|}{ Scopolamine Dose (mg) } \\
\hline & 0.0 & 0.5 & 0.8 \\
\hline & \multicolumn{3}{|c|}{ Free Recall (number correct) } \\
\hline Immediate (out of 70 ) & 44.2 & 40.2 & 32.6 \\
\hline \multirow[t]{2}{*}{ Delayed (out of 14) } & 7.5 & 5.8 & 3.1 \\
\hline & \multicolumn{3}{|c|}{ New Map Test (percent correct) } \\
\hline Trial 1 & 35.6 & 31.1 & 21.9 \\
\hline Trial 2 & 67.0 & 57.0 & 37.2 \\
\hline Trial 3 & 80.3 & 68.6 & 49.2 \\
\hline \multirow[t]{2}{*}{ Trial 4} & 88.9 & 76.4 & 56.4 \\
\hline & \multicolumn{3}{|c|}{ Brown-Peterson STM } \\
\hline Number correct (out of 40) & 24.8 & 17.8 & 7.7 \\
\hline Omissions & 12.1 & 18.1 & 29.2 \\
\hline Prior-item intrusions & 1.8 & 1.8 & 1.1 \\
\hline Extralist intrusions & 1.3 & 2.3 & 2.1 \\
\hline Percent perseverations & 7.7 & 8.5 & 10.4 \\
\hline
\end{tabular}

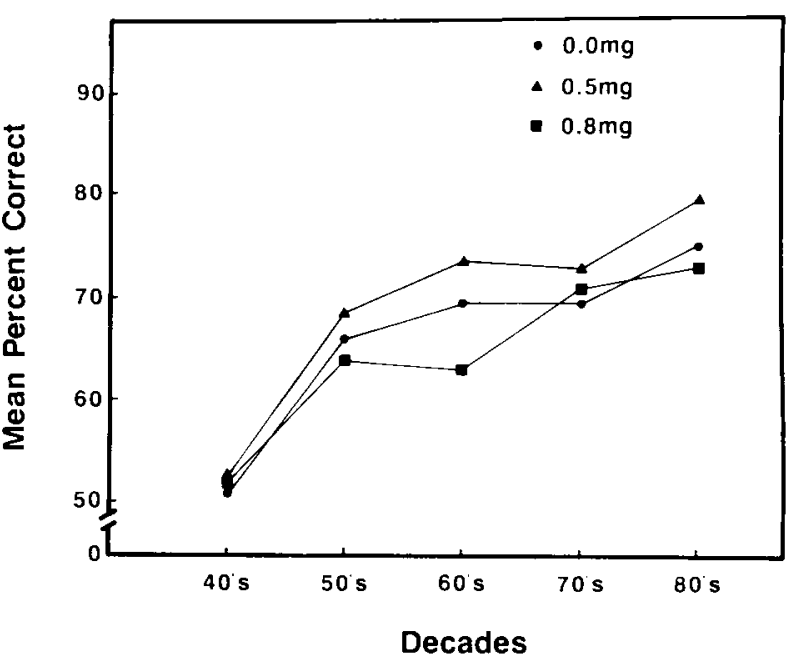

Figure 1. Mean percent correct on remote memory items from various decades after scopolamine or placebo treatment. Data for famous faces and public events have been pooled.

effects of drug dose $[F(2,22)=11.31, p<.001]$ and trials $[F(3,33)=68.92, p<.001]$, but the drug dose $\times$ trials interaction was not significant. Subsequent $t$ tests revealed that performance with the high dose was inferior to that with the other two treatment conditions $(p s<.05)$. The slight impairment in new map learning after treatment with the low dose was not statistically significant.

On the Brown-Peterson short-term memory test, scopolamine treatment reduced the number of words correctly recalled in a dose-dependent manner $[F(2,22)=$ $33.35, p<.001]$, primarily because the subjects made more errors of omission under the influence of the drug $[F(2,22)=30.70, p<.001]$ (see Table 1). Subsequent $t$ tests showed that performance under each of the three drug conditions was significantly different from the other two drug conditions on both of the above measures (all $p s<.05)$. Scopolamine did not affect the number of prior-item $[F(2,22)=1.04, p>.10]$ or extralist $[F(2,22)$ $=1.67, p>.10]$ intrusions. Since drug treatment reduced the total number of words produced on the recall tests, the percentage of perseverative responses (the proportion of prior item plus repeated extralist intrusions) was computed. Scopolamine treatment failed to affect performance on this measure $(F<1)$.

\section{Remote-Memory Tests}

Overall performance on the remote-memory battery is shown in Figure 1 and Table 2. In Table 2, performance is averaged across decades.

ANOVA revealed no significant effect of scopolamine treatment $[F(2,22)=1.80, p>.10]$. In fact, overall performance was slightly higher following the $0.5-\mathrm{mg}$ dose than it was after either saline or $0.8 \mathrm{mg}$ scopolamine administration. There was a significant effect of decades $[F(4,44)=11.53, p<.001]$, which arose because ac- 
Table 2

Mean Performances on the Remote-Memory Measures

\begin{tabular}{lccr}
\hline & \multicolumn{3}{c}{ Scopolamine Dose (mg) } \\
\cline { 2 - 4 } Task & 0.0 & 0.5 & 0.8 \\
\hline Remote-memory battery* & 66.3 & 70.2 & 64.8 \\
& & Fargo Map Test \\
U.S. map* & 91.6 & 89.5 & 87.8 \\
Regional map (ND-SD-MN)* & 80.4 & 77.1 & 74.7 \\
& & Verbal Fluency & \\
Number of correct words & & & \\
FAS & 48.4 & 52.5 & 44.1 \\
Animals & 23.0 & 22.0 & 19.1 \\
Repetitions & & & \\
FAS & 2.7 & 3.7 & 2.6 \\
Animals & 1.1 & 0.6 & 1.0 \\
Percent perseverations & & & \\
FAS & 5.2 & 5.8 & 4.7 \\
Animals & 4.9 & 2.9 & 4.8 \\
\hline
\end{tabular}

*Percent correct.

curacy in recalling items from the 1940 s was lower than that for any other decade (all $p s<.02$ ). Since the majority of the subjects were born after 1949 , this finding is not surprising. Furthermore, the drug $\times$ decade interaction was not significant $(F<1)$, indicating that scopolamine had no effect on remote memory at any decade.

Further evidence that scopolamine treatment did not impede the retrieval of information from remote memory came from our subjects' performance on the FMT (Table 2). On this task, the main effect of drug dose did not attain statistical significance for either the U.S. or the regional $(\mathrm{ND}, \mathrm{SD}, \mathrm{MN})$ maps $[F(2,22)=2.87, p>.05$; and $F(2,22)=2.04, p>.10$, respectively].

Scopolamine administration had no effect upon any aspect of performance on the letter-fluency test (i.e., FAS), another measure of retrieval from semantic memory (Table 2). Neither dose of scopolamine reduced output relative to saline $[F(2,22)=3.00, p>.05]$, and neither dose increased the number of repetitions $[F(2,22)$ $=1.07, p>.10]$. The percentage of perseverative responses (repetitions) relative to output also showed no significant change across drug conditions $(F<1)$.

On the measure of retrieval of information by category (the Animals portion of the verbal-fluency test), there was a significant main effect of drug dose on output $[F(2,22)$ $=4.12, p<.05]$, but the number of repetitions and the percent perseverative responses were comparable across the three levels of drug treatment (both $F \mathrm{~s}<1$ ). Subsequent $t$ tests revealed that output differed significantly between the saline placebo and the $0.8-\mathrm{mg}$ scopolamine conditions $(p<.05)$; other comparisons indicated no significant differences. Thus, administration of $0.8 \mathrm{mg}$ scopolamine decreased output on the Animals portion of the verbal-fluency test, but a similar change did not occur on the FAS portion of this task.

A case of delirium following scopolamine administration. One subject (aged 59) became delirious after receiving each dose of scopolamine, and his incomplete data were excluded from the statistical analyses. Following scopolamine administration, he exhibited incoherent speech, hallucinations, and profound impairment of attention. At the higher dose, he was disoriented to both time and place and was unable to produce a single word beginning with the letter $F$ in four attempts. Attempts to administer the more complicated tests in the battery (the NMTs and Brown-Peterson STM tests) were unsuccessful, apparently because he failed to comprehend the instructions.

Despite these profound disturbances in cognitive function, the subject's performance on the remote-memory battery and the FMT was only mildly impaired by the $0.5-\mathrm{mg}$ dose of scopolamine (e.g., $50 \%$ correct on the RMB vs. $56 \%$ after saline). His performance on these tests was severely impaired at the higher dose, but, because of his delirium, it is impossible to attribute his poor performance to a specific inability to retrieve remote memories.

\section{DISCUSSION}

In agreement with previous studies with humans and other species (Collerton, 1986; Spencer \& Lal, 1983), the present experiment demonstrated dose-related impairments on all three measures of anterogade memory following scopolamine administration. In contrast, the scopolamine treatment had no significant effect on measures of remote memory that did not place a premium on rapid responding: identification of famous people, recall of past public events, or locating geographical features on outline maps.

On the verbal-fluency tests, a modest disruption of output at the $0.8-\mathrm{mg}$ dose was observed when subjects were required to produce names of animals, but no deficits were observed on the letter-fluency task (i.e., the FAS). In earlier work, Caine et al. (1981) found that the generation of semantically (i.e., categorically) related and semantically unrelated words was differentially affected by scopolamine treatment in a manner similar to our results. In their study, treatment with $0.8 \mathrm{mg}$ scopolamine depressed output on the letter-fluency task, but this effect was only evident during the second minute of their 2-min test. Caine et al. (1981) found deficits in the production of semantically related words (e.g., animals) during the first minute of testing following $0.8-\mathrm{mg}$ scopolamine treatment (as in the present study, which used 1-min tests).

To better understand why scopolamine depressed output on the Animals portion of the verbal-fluency task but did not affect performance on other measures of remote memory, we computed difference scores between performance after treatment with saline or $0.8 \mathrm{mg}$ scopolamine for each of the 12 subjects on the various dependent variables. The change in performance caused by this dose of the drug on the Animals measure was significantly correlated with the change in performance due to drug on 
the letter-fluency task (FAS), the free-recall task, and the NMT $(r \mathrm{~s}>0.61, p s<.05)$, but a similar correlation between changes in performance on the Animals task and the remote-memory battery was not significant $(r=0.19)$. These findings suggest that normal performances on verbal-fluency tasks and on some measures of anterograde memory depend, in part, upon similar drug-sensitive cognitive processes, which are less important for successful performance on other measures of remote memory that do not emphasize sustained and rapid responding. The identity of these processes is not clear at present.

The present findings are consistent with the results of many previous animal studies (Beatty \& Bierley, 1985; Burešová et al., 1986; Santi et al., 1987; Whishaw, 1985; Wirsching et al., 1984) that indicate that performance on many measures of anterograde memory can be disrupted by moderate doses of anticholinergic agents that have minimal effects on retrieval of established memories. Deficits on reference-memory tasks have been observed at higher doses (Burešová et al., 1986; Santi et al., 1987). It is possible, therefore, that we would have observed deficits on most or all of our remote-memory measures if we had increased the scopolamine dose. Such deficits would be difficult to interpret, however, since they probably would occur in the context of some degree of toxic delirium.

The present findings may have important implications for pharmacological models of the memory failure associated with Alzheimer's disease (AD). Autopsy studies of $\mathrm{AD}$ patients demonstrate degeneration of cholinergic neurons in the basal forebrain as well as reduced levels of the cholinergic markers, choline acetyltransferase and acetylcholinesterase, in cortical and limbic sites (Fuld, Katzman, Davies, \& Terry, 1982; Perry et al., 1978; Whitehouse, Price, Clark, Coyle, \& Delong, 1981). While alive, patients with AD show impairments on most measures of anterograde memory (e.g., Butters et al., 1983; Flicker, Bartus, Crook, \& Ferris, 1984; Morris, 1986; Moss, Albert, Butters, \& Payne, 1986) and also exhibit deficits in output on letter- and category-fluency tasks (Butters, Granholm, Salmon, Grant, \& Wolfe, 1987; Martin \& Fedio, 1983; Ober, Dronkers, Koss, Delis, \& Friedland, 1986; Rosen, 1980). Because scopolamine administration disrupts both anterograde memory and verbal fluency in normal subjects, Weingartner (1985) proposed that administration of this drug models a dementialike memory disorder.

Two aspects of the present findings reveal limitations of this model. First, the impaired performance of AD patients on the Brown-Peterson STM test (Beatty et al., 1986) and on verbal-fluency tasks (Butters et al., 1987; Ober et al., 1986; Rosen, 1980) is accompanied by increases in the number and proportion of perseverative errors (intrusions and repetitions). In agreement with earlier work (Beatty et al., 1986), we found no increase in perseverative responding after scopolamine treatment on the STM test or on either of the verbal-fluency measures in the present study. In other experiments (Caine et al., 1981; Drachman \& Leavitt, 1974; Sunderland et al., 1987) in which scopolamine was found to depress output on fluency tests, data on perseverative responding were not reported. Two studies (Firth et al., 1984; Mewaldt \& Ghoneim, 1979), however, have failed to observe increases in perseverative responding after treatment with scopolamine at doses sufficient to impair verbal learning. The absence of an effect of scopolamine on perseverative responding may be a fairly general finding.

The second difficulty for the scopolamine model of memory failure in dementia is the absence of any discernible drug effect on measures of remote memory that do not emphasize sustained and rapid responding (i.e., the remote-memory battery and the FMT used in the present study). Previous research (Flicker, Ferris, Crook, \& Bartus, 1987; Sagar, Cohen, Corkin, \& Growdon, 1985; Wilson, Kaszniak, \& Fox, 1981) has shown that AD patients are severely impaired in identifying famous people and recalling past public events. In a more recent study, Beatty, Salmon, Butters, Heindel, and Granholm (1988) compared the performance of mildly and moderately demented $\mathrm{AD}$ patients to that of age- and education-matched controls, using the same battery of famous faces and public events questions employed in the present study. Under conditions of unaided recall, the AD patients averaged $11 \%$ correct, while the controls averaged $63 \%$ correct. These findings demonstrate that severe disturbances on these measures of remote memory occur early in the course of AD. While little information is available on the state of geographic knowledge in AD patients, our preliminary results with the FMT indicate that mildly to moderately demented patients have considerable difficulty in accurately locating specific geographical features (i.e., cities), although they often retain the ability to locate gross geographical features (e.g., oceans).

In 1974, Drachman and Leavitt reported that scopolamine treatment had no significant effect on the WAIS verbal IQ score, which primarily measures well-established knowledge. Although verbal IQ eventually declines in $\mathrm{AD}$, it has been repeatedly found that the verbal subtests of the WAIS are relatively insensitive measures of impairment in the early stages of this disease (Alexander, 1973; Ferris, Crook, Clark, McCarthy, \& Rae, 1980; Gutzmann, Klimitz, \& Avdaloff, 1982). Consequently, the absence of an effect of scopolamine on verbal IQ poses no problem for the hypothesis that scopolamine administration provides an adequate experimental model of the memory failure observed in AD. Indeed, if such a model is intended to simulate only the cognitive changes that appear early in the course of $\mathrm{AD}$ when degeneration of basal forebrain cholinergic systems may represent the most prominent neuropathological change, then the absence of an influence of scopolamine on verbal IQ could be taken as support for the adequacy of this drug model of memory loss in dementia. The failure of scopolamine to affect other measures of remote memory, on which mildly and moderately demented AD patients are severely impaired, 
however, demonstrates that scopolamine treatment does not adequately approximate the full spectrum of memory deficits that occur early in AD. The present findings also demonstrate that reliance upon a single measure of "knowledge" memory, such as verbal fluency, can lead to misleading conclusions.

\section{REFERENCES}

AlEXANDER, D. A. (1973). Some tests of intelligence and learning for elderly psychiatric patients: A validation study. British Journal of Social \& Clinical Psychology, 12, 188-193.

Albert, M. S., ButTers, N., \& Levin, J. (1979). Temporal gradients in the retrograde amnesia of patients with alcoholic Korsakoff's disease. Archives of Neurology, 36, 211-216.

American Psychological Association. (1972). Guidelines for psychologists for the use of drugs in research. American Psychologist, 27, 336.

american Psychological Association. (1981). Ethical principles of psychologists. American Psychologist, 36, 633-638.

Bartus, R., Dean, R., Beer, B., \& LipPa, A. (1982). The cholinergic hypothesis of geriatric memory dysfunction. Science, 217, 408-417.

Beatty, W. W. (1988). The Fargo Map Test: A standardized method for assessing remote memory for visuospatial information. Journal of Clinical Psychology, 44, 61-67.

BEATTY, W. W., \& BiERLEY, R. A. (1985). Scopolamine degrades spatial working memory but spares spatial reference memory: Dissimilarity of anticholinergic effect and restriction of distal visual cues. Pharmacology, Biochemistry \& Behavior, 23, 1-6.

Beatty, W. W., Butters, N., \& Janowsky, D. (1986). Patterns of memory failure after scopolamine treatment: Implications for cholinergic hypotheses of dementia. Behavioral \& Neural Biology, 45, 196-211.

Beatty, W. W., Salmon, D. P., Bernstein, N., \& Butters, N. (1987). Remote memory in a patient with amnesia due to hypoxia. Psychological Medicine, 17, 657-665.

Beatty, W. W., Salmon, D. P., Butters, N., Heindel, W. C., \& Granholm, E. L. (1988). Retrograde amnesia in patients with Alzheimer's disease or Huntington's disease. Neurobiology of Aging, 9, 181-186.

Borkowski, J., BENTON, A., \& SPREEN, O. (1967). Word fluency and brain damage. Neuropsychologia, 5, 135-140.

Burešoví, O., BolHuis, J. J., \& BurEš, J. (1986). Differential effects of cholinergic blockade on performance of rats in a water tank navigation task and in a radial water maze. Behavioral Neuroscience, $100,476-482$.

Butters, N., Albert, M. S., Sax, D., Miliotis, P., Nagode, J., \& STERSTE, A. (1983). The effects of verbal mediators on the pictorial memory of brain-damaged patients. Neuropsychologia, 21, 307-323.

Butters, N., Granholm, E., Salmon, D. P., Grant, I., \& Wolfe, J. (1987). Episodic and semantic memory: A comparison of amnesic and demented patients. Journal of Clinical \& Experimental Neuropsychology, 9, 479-497.

Caine, E., Weingartner, H., Ludlow, C., Cudahy, E., \& Wehry, S. (1981). Qualitative analysis of scopolamine-induced amnesia. Psychopharmacology, 74, 74-80.

Collerton, D. (1986). Cholinergic function and intellectual decline in Alzheimer's disease. Neuroscience, 19, 1-28.

Crow, T., \& Grove-WhITE, I. (1973). An analysis of the learning deficit following hyoscine administration to man. British Journal of Pharmacology, 49, 322-327.

Derogatis, B. (1977). SCL-90-R Manual-1. Baltimore: Johns Hopkins University Press.

Drachman, D., \& LeAvitT, J. (1974). Human memory and the cholinergic system. Archives of Neurology, 30, 113-121.
Ferris, S. H., Crook,T., Clark, E., McCarthy, M., \& Rae, D. (1980). Facial recognition memory deficits in normal aging and senile dementia. Journal of Gerontology, 35, 707-714.

Flicker, C., Bartus, R., Crook, T., \& Ferris, S. (1984). Effects of aging and dementia upon recent visuospatial memory. Neurobiology of Aging, 5, 127-130.

Flicker, C., Ferris, S. H., Crook, T. \& Bartus, R. T. (1987). Implications of memory and language dysfunction in the naming deficit of senile dementia. Brain \& Language, 31, 187-200.

Frith, C., Richardson, J., Samuel, M., Crow, T., \& McKenna, P. (1984). The effects of intravenous diazepam and hyoscine upon human memory. Quarterly Journal of Experimental Psychology, 36A, 133-144.

Fuld, P., Katzman, R., Davies, P., \& Terry, R. (1982). Intrusions as a sign of Alzheimer's disease: Chemical and pathological verification. Annals of Neurology, 11, 155-159.

GHoneim, M., \& MEWALDT, S. (1975). Effects of diazepam and scopolamine on storage, retrieval and organizational processes in memory. Psychopharmacologia, 44, 257-262.

Gutzmann, H., Klimitz, H., \& Avdaloff, W. (1982). Correlations between psychopathology, psychological test results and computerized tomography changes in senile dementia. Archives of Gerontology \& Geriatrics, 1, 241-259.

LeVy, A., Kluge, P. B., \& Elsmore, T. B. (1983). Radial arm maze performance of mice: Acquisition and atropine effects. Behavioral \& Neural Biology, 39, 229-240.

MARTIN, A., \& FEDIO, P. (1983). Word production and comprehension in Alzheimer's disease: The breakdown of semantic knowledge. Brain \& Language, 19, 124-141.

Mewaldt, S., \& Groneim, M. (1979). The effects and interactions of scopolamine, physostigmine, and methamphetamine on human memory. Pharmacology, Biochemistry \& Behavior, 10, 1205-1210.

MorRIs, R. G. (1986). Short-term forgetting in senile dementia of the Alzheimer's type. Cognitive Neuropsychology, 3, 77-97.

Moss, M., Albert, M. S., Butters, N., \& Payne, M. (1986). Differential patterns of memory loss among patients with Alzheimer's disease, Huntington's disease, and alcoholic Korsakoff's syndrome. Archives of Neurology, 43, 239-246.

Ober, B., Dronkers, N., Koss, E., Delis, D., \& Friedland, R. (1986). Retrieval from semantic memory in Alzheimer-type dementia. Joumal of Clinical \& Experimental Neuropsychology, 8, 75-92.

OKaICHI, H., \& JARRARD, L. E. (1982). Scopolamine impairs performance on a place and cue task in rats. Behavioral \& Neural Biology, 36, 319-325.

Perry, E., Tomlinson, B., Blessed, G., Bergmann, K., Gibson, P., \& Perry, R. (1978). Correlations of cholinergic abnormalities with senile plaques and mental test scores in senile dementia. British Medical Journal, 2, 1457-1459.

Rosen, W. G. (1980). Verbal fluency in aging and dementia. Journal of Clinical Neuropsychology, 2, 135-146.

Sagar, H., Cohen, N., Corkin, S., \& Growdon, J. (1985). Dissociations among processes in remote memory. Annals of the New York Academy of Sciences, 444, 533-535.

Santi, A., Hanemaayer, C., \& Reason, W. (1987). The effect of scopolamine on reference and working memory in pigeons. Animal Learning \& Behavior, 15, 395-402.

Sitaram, N., WeingarTner, H., \& Gillin, J. C. (1978). Human serial learning: Enhancement with arecholine and choline and impairment with scopolamine. Science, 201, 274-276.

SPENCER, D. G., \& LAL, H. (1983). Effects of anticholinergic drugs on learning and memory. Drug Development Research, 3, 489-502.

Sunderland, T., Tariot, P., Cohen, R., Weingartner, H., MUELler, E., \& MURPHY, D. (1987). Anticholinergic sensitivity in patients with dementia of the Alzheimer type and age-matched controls: A dose-response study. Archives of General Psychiatry, 44, 418-426.

WeingarTNER, H. (1985). Models of memory dysfunctions. Annals of the New York Academy of Science, 44, 359-369. 
Whishaw, I. Q. (1985). Cholinergic receptor blockade in the rat impairs locale but not taxon strategies for place navigation in a swimming pool. Behavioral Neuroscience, 99, 979-1005.

Whitehouse, P. J., Price, D. L., Clark, A. W., Coyle, J. T., \& DELONG, M. R. (1981). Alzheimer's disease: Evidence for selective loss of cholinergic neurons in the nucleus basalis. Annals of Neurology, 10, 122-126.

Wilson, R., KASZniak, A., \& Fox, J. (1981). Remote memory in senile dementia. Cortex, 17, 41-48.
Wirsching, B., Beninger, R., Jhamandas, K., Boegman, R., \& ElDEFrawy, S. (1984). Differential effects of scopolamine on working and reference memory of rats in the radial maze. Pharmacology, Biochemistry \& Behavior, 20, 659-662.

(Manuscript received March 4, 1988; revision accepted for publication August 15, 1988.)

\section{NOTICE}

\section{Nominations for Editorship of Psychobiology}

Nominations are solicited for the editorship of Psychobiology. The term of the present editor, Lynn Nadel, will end in 1990. The new editor will begin an official 4-year term in 1990, and will begin to receive manuscripts in 1989 .

Nominations must be submitted by April 30, 1989.

Nominations (including self-nominations) should be sent to:

C. R. Gallistel

Department of Psychology

University of Pennsylvania

Philadelphia, PA 19104 